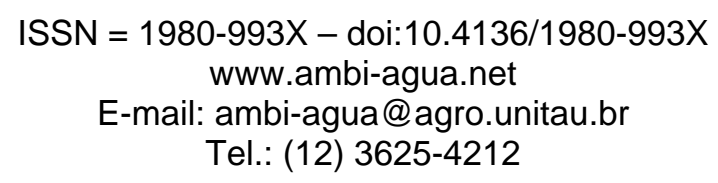

\title{
Avaliação espacial e temporal da qualidade da água na sub-bacia do rio Poxim, Sergipe, Brasil \\ (doi:10.4136/ambi-agua.178)
}

\section{Anderson Nascimento do Vasco ${ }^{1}$; Fábio Brandão Britto ${ }^{1}$; Ana Paula Sousa Pereira ${ }^{1}$; Arisvaldo Vieira Méllo Júnior ${ }^{2}$; Carlos Alexandre Borges Garcia ${ }^{3}$; Luis Carlos Nogueira $^{4}$}

\author{
${ }^{1}$ Programa de Pós-Graduação em Agroecossitema, Universidade Federal de Sergipe - UFS \\ E-mail: anderovasco@yahoo.com.br; brandaobritto@hotmail.com; bioanap_va@hotmail.com \\ ${ }^{2}$ Departamento de Engenharia Hidráulica da Universidade de São Paulo - USP \\ E-mail: arimello@gmail.com \\ ${ }^{3}$ Departamento de Química da Universidade Federal de Sergipe - UFS \\ E-mail: carlosabgarcia@hotmail.com \\ ${ }^{4}$ Embrapa Cocais e Planícies Inundáveis - EMBRAPA \\ E-mail: lcnogueira@gmail.com
}

\section{RESUMO}

A dinâmica de uso e ocupação do solo na sub-bacia hidrográfica do rio Poxim, em Sergipe, é fator determinante para o comprometimento da qualidade das suas águas. Este estudo teve o objetivo de avaliar a qualidade da água associado com aspectos relacionados ao uso e ocupação do solo, em quatro diferentes estações de monitoramento no período chuvoso e seco. Os parâmetros avaliados foram pH, OD, DBO, DQO, turbidez, Sólidos Dissolvidos Totais (SDT), fósforo total, nitrogênio amoniacal, nitrito e nitrato, no período de julho de 2009 a junho de 2010. As amostras de água foram coletadas em quatro estações de monitoramento (E1, no rio Poxim-Mirim; E2, no rio Poxim-Açu; E3, no rio Poxim, próxima à confluência dos dois afluentes citados; e E4, no ponto de captação para abastecimento público da Companhia de Saneamento de Sergipe) e analisadas no Laboratório de Química Analítica da Universidade Federal de Sergipe (UFS). Os resultados foram comparados aos padrões brasileiros de qualidade para as águas doces (Classe 2), conforme a Resolução CONAMA n 357/2005. DBO e DQO mostraram maior aporte de matéria orgânica, na estação E3. OD apresentou valores críticos nas quatro estações. Os nutrientes nitrogênio e fósforo apresentaram maiores concentrações nas estações E1 e E2 (parte alta da sub-bacia, com características agrícolas). A parte baixa da sub-bacia apresentou uma elevada degradação da qualidade da água devido ao processo de urbanização. Os parâmetros estudados indicam a baixa qualidade da água na sub-bacia do rio Poxim e a necessidade de adoção de medidas mitigatórias apropriadas.

Palavras-chave: Monitoramento ambiental; recursos hídricos; qualidade da água.

\section{Assessing the spatial and temporal water quality in the sub-basin of the Poxim river, Sergipe state, Brazil}

\section{ABSTRACT}

The dynamics of the land use and cover in the Poxim river basin, in Sergipe, Brazil, is a determinant factor for reducing the superficial water quality. This study aimed to identify aspects of water quality related to the land use and cover in four different monitoring stations, in the rainy and dry season. The monitored parameters were $\mathrm{pH}, \mathrm{DO}, \mathrm{BOD}, \mathrm{COD}$, turbidity, total dissolved solids (TDS), total phosphorus, ammonia, nitrite and nitrate, between July 2009 and June 2010. Water samples were collected at four monitoring stations (E1, in the Poxim-Mirim River; E2, in the Poxim-Açu River; E3, in the main river, near the confluence 
VASCO, A. N.; BRITTO, F. B.; PEREIRA, A. P. S.; MÉLlO JÚNIOR, A. V. M.; GARCIA, C. A. B.; NOGUEIRA, L. C. Avaliação espacial e temporal da qualidade da água na sub-bacia do rio Poxim, Sergipe, Brasil. Ambi-Agua, Taubaté, v. 6, n. 1, p. 118-130, 2011. (doi:10.4136/ambi-agua.178)

of the two tributaries; and E4, at the Sanitation Company of Sergipe State water supply intake) and analyzed at the Laboratory of Analytical Chemistry of the Federal University of Sergipe State. The results were compared with Brazilian standards for fresh water quality (Class 2), according to CONAMA Resolution $n^{\circ} 357 / 2005$. BOD and COD showed a higher input of organic matter in the monitoring station E3. OD values were critical in all four stations. The nutrients nitrogen and phosphorus had higher concentrations at stations E1 and E2 (upper basin, with agricultural practices). In the lower basin, there is a considerable deterioration of water quality, possibly due to the urbanization process. The studied parameters indicate the low quality of water in the Poxim River basin and the need to adopt appropriate mitigation measures.

Keywords: Environmental monitoring; water resources; water quality.

\section{INTRODUÇÃO}

Nos últimos anos, vários estudos têm sido realizados com o intuito de investigar os problemas relacionados com a redução da qualidade da água para o abastecimento público, lazer, irrigação, entre outros, levando a identificação das fontes poluidoras, bem como a elaboração de propostas para o seu controle (Franco e Hernandez, 2009; Silva et al., 2009; Rocha et al., 2010).

A crescente contaminação dos recursos hídricos, causada por diversas fontes, dentre as quais se destacam os efluentes domésticos, os efluentes industriais e a carga difusa urbana e agrícola, vem comprometendo o uso desses recursos para os seus diversos fins. Cada uma dessas fontes possui características próprias quanto aos poluentes. A poluição das águas por efluentes domésticos e industriais é uma das maiores causas da redução na qualidade da água, aumentando os custos de tratamento para consumo humano. Dessa forma, a avaliação e o monitoramento da água são fundamentais para acompanhar o comportamento dos parâmetros físico-químicos, alem de fornecer subsídios para avaliar as condições do manancial e contribuir com informações para tomada de decisões no gerenciamento dos recursos hídricos (Figueirêdo, 2008).

O estudo em áreas de bacias hidrográficas urbanas e rurais é imprescindível quando se busca o equilíbrio entre a exploração de recursos naturais e sustentabilidade ambiental. $\mathrm{O}$ processo evolutivo de ocupação de tais áreas se manifesta de maneira desordenada, impulsionado pelo crescimento acelerado da população, expansão das áreas agrícolas e intensa urbanização. Isso traz graves e irreversíveis modificações ambientais na dinâmica natural dos ecossistemas associados a essas áreas (Melo Neto et al., 2008; Silva et al., 2006).

Esse problema pode ser observado em diversas bacias hidrográficas, indicando a necessidade de estudos integrados que contemplem a compreensão do funcionamento básico dessas bacias, e gerando subsídios para programas de monitoramento da qualidade da água em recursos hídricos localizados próximos a centros urbanos.

Sabe-se que as alterações nas características das águas superficiais estão relacionadas ao uso e à ocupação do solo da sua bacia hidrográfica de drenagem, com a cobertura vegetal e, principalmente, com os diversos tipos de ação antrópica existente (Pedroso et al., 1988; Araújo, 2000). Para uma melhor compreensão dos ecossistemas aquáticos, é preciso avaliar a bacia hidrográfica, de forma integrada, buscando entender a interação entre os ambientes aquáticos e terrestres.

Nesse contexto, insere-se a importância do estudo na sub-bacia do rio Poxim, por apresentar as principais características inerentes aos cursos d’água que têm seu curso principal localizado em áreas de regiões metropolitanas e em áreas agrícolas, elevada concentração de poluentes domésticos e industriais, ausência quase que completa da vegetação ciliar, grandes extensões de culturas agrícolas, assoreamento em diversos trechos, desde a nascente até a foz, e fauna aquática reduzida. O que caracteriza, geralmente, tais 
VASCO, A. N.; BRITTO, F. B.; PEREIRA, A. P. S.; MÉLlO JÚNIOR, A. V. M.; GARCIA, C. A. B.; NOGUEIRA, L. C. Avaliação espacial e temporal da qualidade da água na sub-bacia do rio Poxim, Sergipe, Brasil. Ambi-Agua, Taubaté, v. 6, n. 1, p. 118-130, 2011. (doi:10.4136/ambi-agua.178)

regiões é a evidente deficiência nas estruturas operacionais de oferta dos serviços de saneamento básico e a limitada ou completa inexistência da aplicação da legislação que norteia a gestão integrada dos recursos hídricos.

Atualmente, a sub-bacia hidrográfica do rio Poxim, que faz parte da bacia do rio Sergipe, está inserida na área metropolitana de Aracaju, e vem apresentando, ao longo da última década, intenso processo de ocupação, em grande parte desordenada, trazendo intervenções que afetam o meio ambiente. Esses impactos ambientais provocam uma grave diminuição na oferta hídrica, causada pelo decréscimo da vazão do rio e pelo aumento da poluição, comprometendo a sua qualidade para abastecimento público (Silva et al., 2004).

O rio Poxim, que no passado contribuiu com $70 \%$ do abastecimento público de Aracaju, passou a fornecer apenas 30\%, havendo perspectivas de diminuir ainda mais esse percentual. O crescimento populacional e a expansão do parque industrial do Estado de Sergipe, que se concentra no entorno da bacia, têm ocasionado o acréscimo progressivo na demanda de água (Silva et al., 2004).

O conhecimento das condições atuais das características físico-químicas da água na subbacia hidrográfica do rio Poxim, e sua comparação com estudos anteriores e com outros ambientes em condições similares permitirão identificar os problemas prioritários para o desenvolvimento de alternativas de solução e de recuperação.

O presente trabalho teve por objetivo analisar os parâmetros físico-químicos da qualidade da água na sub-bacia do rio Poxim relacionando o uso e a ocupação do solo com possíveis interferências na qualidade da água, visando contribuir com informações úteis para a gestão dos recursos hídricos dessa sub-bacia hidrográfica.

\section{MATERIAIS E MÉTODOS}

\subsection{Descrição da área}

O Estado de Sergipe é constituído por 75 municípios, possui uma área total de 22.050 $\mathrm{km}^{2}$, com seis bacias hidrográficas que apresentam cenários distintos quanto aos recursos hídricos. Todas as bacias hidrográficas do Estado apresentam zonas com clima do semiárido, do agreste (área de transição) e do litoral. Essa diversidade climática acarreta diferentes condições de armazenamento de seus recursos hídricos (Lucas et al., 2010).

A sub-bacia hidrográfica do rio Poxim está situada entre as coordenadas geográficas $11^{\circ} 01^{\prime}$ e $10^{\circ} 47^{\prime}$ de latitude sul e $37^{\circ} 01^{\prime}$ e $37^{\circ} 24^{\prime}$ de longitude oeste, faz parte da bacia do rio Sergipe e está inserida na região metropolitana da Grande Aracaju. Dos nove municípios que compõem a região metropolitana de Aracaju, cinco deles têm seu território total ou parcialmente dentro da área de abrangência da sub-bacia hidrográfica: Aracaju, São Cristóvão, Nossa Senhora do Socorro, Laranjeiras e Itaporanga D’Ajuda. A única exceção é o município de Areia Branca, que tem parte de seu território dentro da área da sub-bacia hidrográfica do rio Poxim, mas não integra a supracitada região metropolitana (Sergipe, 2004).

\subsection{Definição dos pontos de amostragem}

As amostras de água foram coletadas em quatro estações distribuídas ao longo da subbacia hidrográfica do rio Poxim. A localização dos pontos de amostragem está indicada na Figura 1. A estação E1 está situada no afluente rio Poxim-Mirim, a estação E2 no afluente rio Poxim-Açu, as estações E3 e E4 estão localizadas no leito principal do rio Poxim, sendo que a E3 está localizada próxima à confluência dos rios Poxim-Mirim e Poxim-Açu e a E4 localizase no ponto de captação para abastecimento público da DESO (Companhia de Saneamento de Sergipe). 
VASCO, A. N.; BRITTO, F. B.; PEREIRA, A. P. S.; MÉllo JÚNIOR, A. V. M.; GARCiA, C. A. B.; NOGUEIRA, L. C. Avaliação espacial e temporal da qualidade da água na sub-bacia do rio Poxim, Sergipe, Brasil. Ambi-Agua, Taubaté, v. 6, n. 1, p. 118-130, 2011. (doi:10.4136/ambi-agua.178)

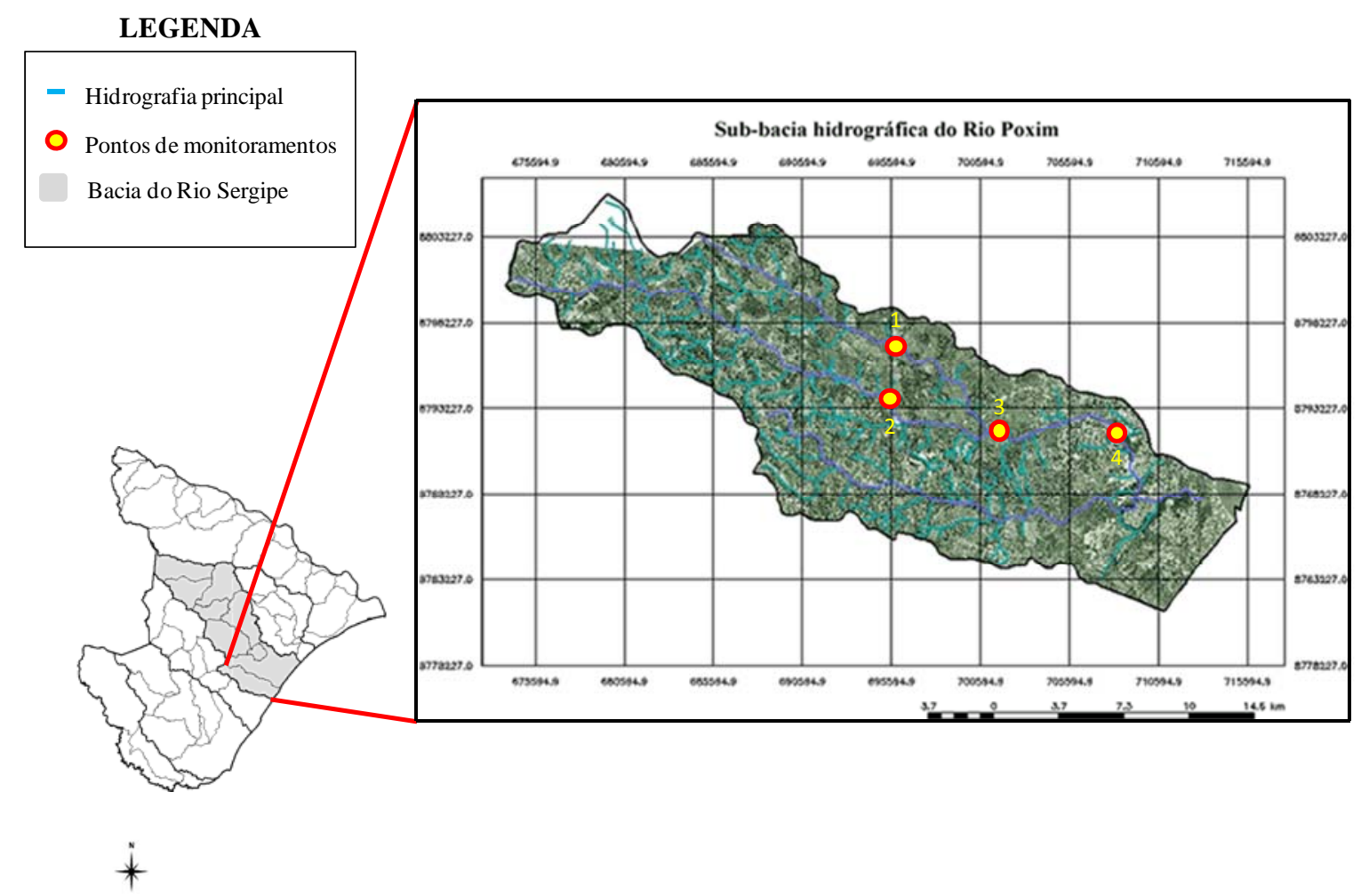

Figura 1. Estações de amostragem de água e determinação da vazão na sub-bacia hidrográfica do rio Poxim, bacia do rio Sergipe, região metropolitana de Aracaju, Sergipe.

Fonte: Sergipe (2004).

As estações de amostragem foram definidas de acordo com as características locais e suas possíveis interferências na qualidade dos recursos hídricos. Com isso, torna-se possível compreender a relação entre o uso e a ocupação do solo da bacia hidrográfica na qualidade da água.

\subsection{Coleta dos dados}

Foram realizadas 12 campanhas mensais de amostragem no período de julho de 2009 a junho de 2010, em cada estação de monitoramento, totalizando um ano completo de dados. As amostras de água foram coletadas na camada superficial, utilizando os procedimentos de coleta e conservação, seguindo os padrões de higiene e controle de amostragem descrita por Agudo (1987) e Macêdo (2003). As análises obedeceram às metodologias descritas no Standard Methods for the Examination of Water and Wastewater (APHA, 2005), Tabela 1.

Tabela 1. Resumo da metodologia analítica adotada (APHA, 2005).

\begin{tabular}{ccc}
\hline Parâmetros & Metodologia & (Standart Methods) \\
\hline pH & Método eletrométrico & $4500 \mathrm{H}$ \\
OD & Método Winkler modificado & $4500-\mathrm{O} \mathrm{C}$ \\
DBO & Diluição e incubação por 5 dias & $5210 \mathrm{~B}$ \\
DQO & Refluxo aberto & $5220 \mathrm{~B}$ \\
Turbidez & Método turbidimétrico & $2130 \mathrm{~B}$ \\
SDT & Gravimétrico & $2540 \mathrm{C}$ \\
Clorofila-a & Determinação espectrofotométrica & $10200 \mathrm{H}$ \\
Fósforo Total & Digestão com persulfato + método do ácido ascórbico & $4500-\mathrm{P} \mathrm{E}$ \\
Nitrato & (ácido ascórbico & $4500-\mathrm{NO}_{3} \mathrm{E}$ \\
Nitrito & Método da redução com Cd & $4500-\mathrm{NO}_{2} \mathrm{~B}$ \\
N- Amoniacal & Método colorimétrico & $4500-\mathrm{NH}_{3} \mathrm{~F}$ \\
\hline
\end{tabular}

Fonte: Adaptado de Alves e Garcia (2006) 
VASCO, A. N.; BRITTO, F. B.; PEREIRA, A. P. S.; MÉLlO JÚNIOR, A. V. M.; GARCIA, C. A. B.; NOGUEIRA, L. C. Avaliação espacial e temporal da qualidade da água na sub-bacia do rio Poxim, Sergipe, Brasil. Ambi-Agua, Taubaté, v. 6, n. 1, p. 118-130, 2011. (doi:10.4136/ambi-agua.178)

\subsection{Estatística descritiva dos dados}

Os dados obtidos no monitoramento e nos cálculos das cargas foram analisados por meio de estudos estatísticos preliminares e de estatísticas básicas sugeridas por Von Sperling (2005). Com isso, foi possível fazer a organização e a caracterização do comportamento das condições de qualidade da água nas quatro estações de monitoramento, que representaram sob diferentes condições de uso e ocupação do solo. As estatísticas básicas foram desenvolvidas em planilhas Excel (Microsoft) para todos os parâmetros analisados neste estudo. Os resultados estatísticos, compreendidos pela caracterização amostral, medidas de tendência central, medidas de variação e medidas de posicionamento relativo, foram representados em tabelas e gráficos do tipo séries temporais.

\section{RESULTADOS E DISCUSSÃO}

\subsection{Parâmetros analisados}

A Tabela 2 apresenta os resultados dos parâmetros de qualidade da água de todas as estações de monitoramento E1 (rio Poxim-Mirim), E2 (rio Poxim-Açu), E3 (Confluência) e E4 (rio Poxim). Houve variação entre os diversos parâmetros estudados, nas diferentes estações de monitoramento, no período chuvoso e seco.

\subsubsection{Temperatura e Oxigênio Dissolvido}

No período seco, a temperatura média da água variou de $26^{\circ} \mathrm{C}$ a $28^{\circ} \mathrm{C}$, enquanto que, no período chuvoso, variou de $23,5^{\circ} \mathrm{C}$ a $25^{\circ} \mathrm{C}$. Esses dados expressam baixa variação, principalmente, ao serem comparados às temperaturas do ar, que na região varia de 25 a $30^{\circ} \mathrm{C}$ (Daltro Filho e Santos, 2001), ou àquelas que possam propiciar elevação da taxa de crescimento biológico e/ou dissolubilidade de $\mathrm{O}_{2}$ na água.

As concentrações médias de oxigênio dissolvido na massa líquida nas áreas estudadas variaram de 2,1 a 4,7 $\mathrm{mg} \mathrm{L}^{-1}$, no período chuvoso, e de 4,3 a 5,6 $\mathrm{mg} \mathrm{L}^{-1}$, no período seco. Esses valores são decorrentes da presença da matéria orgânica (esgotos) e da própria característica física (relevo) dos trechos dos rios, que propicia baixa velocidade no fluxo da água influenciando numa menor reaeração nas estações E3 e E4. Segundo a Resolução CONAMA n ${ }^{0}$ 357/2005, esses trechos seriam enquadrados Classe 3 (Figura 2).
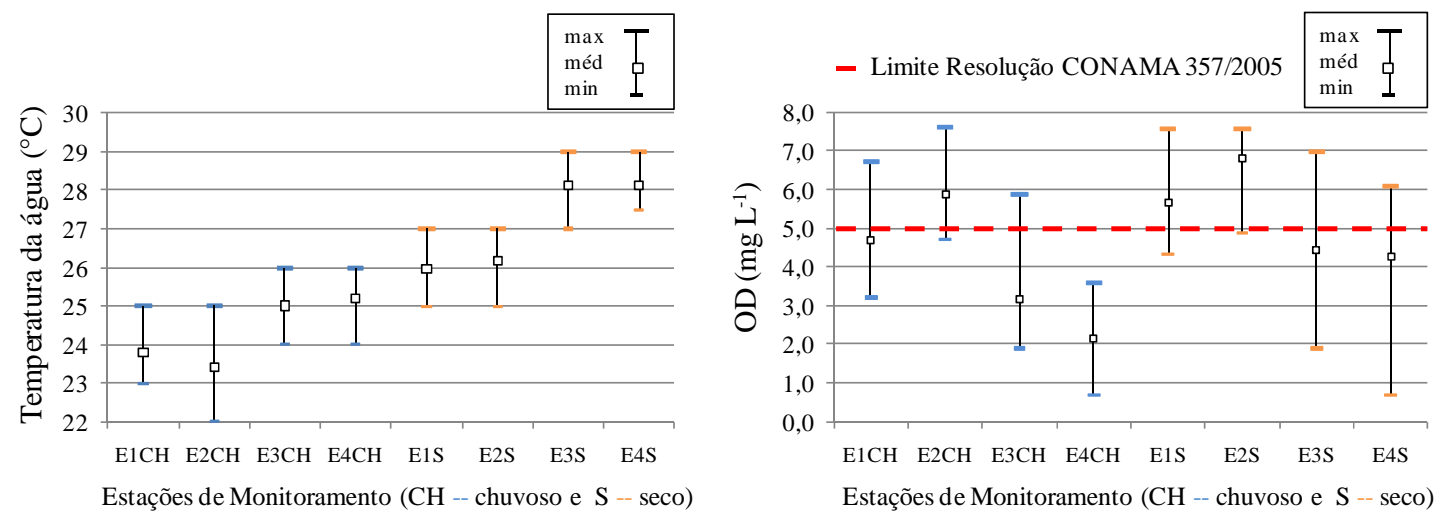

Figura 2. Valores máximos, médios e mínimos de temperatura e oxigênio dissolvido (OD) na bacia do rio Poxim, Sergipe, no período chuvoso e seco, nas diferentes estações de monitoramento.

Os resultados obtidos em períodos chuvoso e seco, nas estações E3 e E4, mostraram concentrações mínimas de oxigênio dissolvido abaixo de $2 \mathrm{mg} \mathrm{L}^{-1}$, ou seja, confirma as condições próximas de anaerobiose do corpo hídrico. Supõe-se que os baixos níveis de oxigênio dissolvido estão relacionados com esgotos sem tratamento lançados no rio. 
VASCO, A. N.; BRITTO, F. B.; PEREIRA, A. P. S.; MÉLlO JÚNIOR, A. V. M.; GARCIA, C. A. B.; NOGUEIRA, L. C. Avaliação espacial e temporal da qualidade da água na sub-bacia do rio Poxim, Sergipe, Brasil. Ambi-Agua, Taubaté, v. 6, n. 1, p. 118-130, 2011. (doi:10.4136/ambi-agua.178)

Tabela 2. Estatísticas descritivas dos parâmetros de qualidade monitorados no período chuvoso e seco para as quatro estações de monitoramento, na sub-bacia hidrográfica do rio Poxim, Sergipe.

\begin{tabular}{|c|c|c|c|c|c|c|c|c|c|}
\hline \multirow{2}{*}{ Parâmetros } & \multirow{2}{*}{ Estação } & \multicolumn{4}{|c|}{ Período Chuvoso } & \multicolumn{4}{|c|}{ Período Seco } \\
\hline & & $\mathbf{N A}^{1}$ & $\operatorname{Max}^{2}$ & $\operatorname{Min}^{3}$ & Méd $^{4}$ & NA & Max & Min & Méd \\
\hline \multirow{4}{*}{$\begin{array}{l}\text { Temperatura da } \\
\text { água }\left({ }^{\circ} \mathrm{C}\right)\end{array}$} & E1 & 5 & 25 & 23 & 23,25 & 7 & 27 & 25 & 26,0 \\
\hline & E2 & 5 & 25 & 22 & 24 & 7 & 27 & 26 & 26,2 \\
\hline & E3 & 5 & 26 & 24 & 24,75 & 7 & 29 & 27 & 28,1 \\
\hline & E4 & 5 & 26 & 24 & 25,5 & 7 & 29 & 27 & 28,1 \\
\hline \multirow{4}{*}{$\mathrm{pH}$} & E1 & 5 & 7,6 & 7,02 & 7,3 & 7 & 8,1 & 6,6 & 7,2 \\
\hline & E2 & 5 & 7,2 & 6,8 & 7,1 & 7 & 8,4 & 6,9 & 7,3 \\
\hline & E3 & 4 & 7 & 6,48 & 6,8 & 6 & 7 & 6,5 & 6,8 \\
\hline & E4 & 3 & 6,6 & 6,2 & 6,3 & 6 & 7,6 & 6,4 & 6,9 \\
\hline \multirow{4}{*}{$\mathrm{OD}\left(\mathrm{mg} \mathrm{L}{ }^{-1}\right.$} & E1 & 5 & 6,71 & 3,2 & 4,67 & 7 & 7,55 & 4,33 & 5,64 \\
\hline & E2 & 5 & 7,61 & 4,7 & 5,88 & 7 & 7,55 & 4,87 & 6,81 \\
\hline & E3 & 4 & 5,86 & 1,89 & 3,17 & 6 & 6,96 & 1,89 & 4,42 \\
\hline & E4 & 2 & 3,58 & 0,68 & 2,13 & 6 & 6,07 & 0,68 & 4,28 \\
\hline \multirow{4}{*}{$\mathrm{DBO}\left(\mathrm{mg} \mathrm{L}^{-1}\right)$} & E1 & 5 & 15,39 & 4,1 & 10,02 & 7 & 29,8 & 3,76 & 11,32 \\
\hline & E2 & 5 & 14,96 & 7,8 & 11,18 & 7 & 21,2 & 4,22 & 11,89 \\
\hline & E3 & 4 & 17,8 & 10,43 & 15,04 & 6 & 14,4 & 2,54 & 9,95 \\
\hline & E4 & 3 & 12,5 & 3,4 & 8,72 & 6 & 14,68 & 2,8 & 7,21 \\
\hline \multirow{4}{*}{ DQO (mg L $\left.{ }^{-1}\right)$} & E1 & 5 & 129 & 22,2 & 78,34 & 7 & 143,48 & 36,9 & 72,21 \\
\hline & E2 & 5 & 120,73 & 13,01 & 67,43 & 7 & 330,01 & 12,45 & 101,21 \\
\hline & E3 & 4 & 858,39 & 42,77 & 293,49 & 6 & 821,86 & 13,6 & 288,45 \\
\hline & E4 & 3 & 54,69 & 28,51 & 41,6 & 6 & 114,38 & 13,6 & 47,9 \\
\hline \multirow{4}{*}{ Turbidez (NTU) } & E1 & 5 & 64,4 & 11,2 & 28,3 & 7 & 132 & 0,1 & 41,7 \\
\hline & E2 & 5 & 179 & 38,6 & 63,1 & 7 & 102 & 0,01 & 32,2 \\
\hline & E3 & 4 & 157 & 17 & 68,8 & 6 & 107 & 0,1 & 35,9 \\
\hline & E4 & 3 & 30,9 & 16,8 & 23,85 & 6 & 128 & 0,1 & 25,7 \\
\hline \multirow{4}{*}{ SDT (mg L ${ }^{-1}$ ) } & E1 & 5 & 166 & 74 & 134,2 & 7 & 394 & 126 & 203,9 \\
\hline & E2 & 5 & 77 & 43 & 62,8 & 7 & 155 & 58 & 86,1 \\
\hline & E3 & 4 & 139 & 38 & 92 & 6 & 202 & 49 & 104,5 \\
\hline & E4 & 3 & 97 & 70 & 84,3 & 6 & 204 & 86 & 122,8 \\
\hline \multirow{4}{*}{ Clorofila-a (ug L ${ }^{-1}$ ) } & E1 & 4 & 44,8 & 3,99 & 19,1 & 5 & 45,3 & 2,12 & 21,24 \\
\hline & E2 & 4 & 50,4 & 0,33 & 16,74 & 5 & 133,8 & 1,34 & 58,15 \\
\hline & E3 & 4 & 134,4 & 4,24 & 37,87 & 5 & 87,8 & 19,17 & 37,14 \\
\hline & E4 & 3 & 117,6 & 4,41 & 72,14 & 4 & 123,2 & 2,58 & 36,41 \\
\hline \multirow{4}{*}{$\begin{array}{l}\text { Fósforo Total (mg } \\
\left.\qquad \mathrm{L}^{-1}\right)\end{array}$} & E1 & 5 & 0,151 & $<$ L.D & 0,076 & 7 & 0,1 & <L.D. & 0,05 \\
\hline & E2 & 5 & 0,523 & 0,1 & 0,176 & 7 & <L.D. & <L.D. & $<$ L.D. \\
\hline & E3 & 4 & 0,344 & 0,018 & 0,171 & 6 & $<$ L.D. & <L.D. & $<$ L.D. \\
\hline & E4 & 3 & $<$ L.D. & $<$ L.D. & $<$ L.D. & 6 & <L.D. & <L.D. & $<$ L.D. \\
\hline \multirow{4}{*}{ Nitrato (mg L $\left.{ }^{-1}\right)$} & E1 & 5 & 5,695 & 0,278 & 1,894 & 7 & 9,11 & 0,751 & 3,279 \\
\hline & E2 & 5 & 5,164 & 0,456 & 1,955 & 6 & 49,201 & 0,629 & 9,048 \\
\hline & E3 & 4 & 3,097 & 0,131 & 1,409 & 5 & 0,871 & 0,562 & 0,699 \\
\hline & E4 & 3 & 1,464 & 0,452 & 0,821 & 5 & 0,923 & 0,28 & 0,544 \\
\hline \multirow{4}{*}{ Nitrito (mg L ${ }^{-1}$ ) } & E1 & 2 & 0,033 & 0,025 & 0,029 & 3 & 0,087 & 0,033 & 0,058 \\
\hline & E2 & 3 & 0,19 & 0,131 & 0,019 & 4 & 0,062 & 0,026 & 0,042 \\
\hline & E3 & 3 & 1,234 & 0,021 & 0,627 & 2 & 0,059 & 0,022 & 0,04 \\
\hline & E4 & 1 & $\mathrm{n} / \mathrm{a}$ & $\mathrm{n} / \mathrm{a}$ & $\mathrm{n} / \mathrm{a}$ & 2 & 0,067 & 0,03 & 0,048 \\
\hline \multirow{4}{*}{ Amônia (mg L ${ }^{-1}$ ) } & E1 & 4 & 0,271 & 0,026 & 0,179 & 4 & 0,204 & 0,062 & 0,106 \\
\hline & E2 & 4 & 0,2962 & 0,006 & 0,117 & 4 & 0,547 & 0,046 & 0,252 \\
\hline & E3 & 4 & 0,753 & 0,029 & 0,433 & 5 & 0,483 & 0,13 & 0,284 \\
\hline & E4 & 3 & 0,424 & 0,328 & 0,339 & 5 & 0,366 & 0,028 & 0,179 \\
\hline
\end{tabular}

$\mathrm{NA}^{1}$ : Número de amostras analisadas. ${ }^{2}$ Valor Máximo. ${ }^{3}$ Valor mínino. ${ }^{4}$ Média Aritmética dos valores. $<$ L.D Valores abaixo do Limite de Detecção do Método (0,01 $\mathrm{mg} \mathrm{L}^{-1}$ fósforo total). 
VASCO, A. N.; BRITTO, F. B.; PEREIRA, A. P. S.; MÉLlO JÚNIOR, A. V. M.; GARCIA, C. A. B.; NOGUEIRA, L. C. Avaliação espacial e temporal da qualidade da água na sub-bacia do rio Poxim, Sergipe, Brasil. Ambi-Agua, Taubaté, v. 6, n. 1, p. 118-130, 2011. (doi:10.4136/ambi-agua.178)

\subsubsection{Demanda Bioquímica de Oxigênio (DBO) e Demanda Química de Oxigênio (DQO)}

Os resultados observados no período chuvoso (12,5 a 17,8 $\left.\mathrm{mg} \mathrm{L}^{-1}\right)$ apresentaram concentrações de DBO máxima inferiores aos resultados obtidos para o período seco $(14,4$ a $29,8 \mathrm{mg} \mathrm{L}^{-1}$ ). Isso ocorreu, provavelmente, devido à diluição promovida pelo período chuvoso. Resultados semelhantes foram encontrados por Daltro Filho e Santos (2001). No entanto, os valores médios de concentração observados foram de 15,04 e 9,95 $\mathrm{mg} \mathrm{L}^{-1}$, na estação E3 no período chuvoso e seco, respectivamente. Esses valores podem ser explicados pela presença de matéria orgânica dos esgotos e de vegetais em decomposição no trecho estudado (Figura 3).

De modo geral, os valores de DBO apresentaram pequena variação entre o período chuvoso e seco, nas estações E1, E2 e E4. Na estação E3, ocorreu o maior valor entre as concentrações médias, com a maior concentração ocorrida no período chuvoso $\left(15,04 \mathrm{~m} \mathrm{~L}^{-1}\right.$ de DBO). Nesse caso, a diluição proporcionada pelo aumento da vazão, no período chuvoso, não foi suficiente para reduzir a concentração de DBO. Pois, nesse período, ocorre um maior lançamento de partículas de solo e material orgânico nos rios o que aumenta a carga orgânica e, consequentemente, o valor da DBO.

Os resultados de DQO indicaram grandes variações entre os valores tanto no período chuvoso quanto no período seco. As causas que podem provocar essa variação são a influência do comportamento hidrológico, características do lançamento de efluentes domésticos, agrícolas e industriais no rio. Para confirmar essa condição seriam necessárias repetições das medidas dos parâmetros, obtendo uma série histórica de dados. Este trabalho obteve apenas um ano de dados em um ano hidrológico considerado favorável no período chuvoso e desfavorável no período seco, sob o ponto de vista de disponibilidade hídrica, comparado com os últimos dez anos.

Devido às altas concentrações de matéria orgânica indicadas pela DBO e DQO, seria de se esperar baixas concentrações de oxigênio dissolvido (OD). Os valores de oxigênio dissolvido abaixo de $5 \mathrm{mg} \mathrm{L}^{-1}$, em período chuvoso e seco nas estações E3 e E4 confirmam as condições mais próximas de anaerobiose do corpo hídrico.

Observa-se pelos valores da Tabela 3 que existe uma condição diferenciada entre as estações amostrais para a relação entre DBO e DQO. Na estação E3, a relação de (0,05 e 0,03 ) indica que a fração biodegradável da matéria orgânica é de apenas $5 \%$ e $3 \%$ no período chuvoso e seco respectivamente, e o restante se constitui de compostos orgânicos não facilmente degradados pelos micro-organismos aeróbios decompositores.

Tabela 3. Relação entre a DBO, DQO média no período chuvoso e seco para as quatro estações de monitoramento, na sub-bacia hidrográfica do rio Poxim, Sergipe.

\begin{tabular}{|c|c|c|c|c|}
\hline \multirow{2}{*}{ DBO : DQO } & Estação 1 & Estação 2 & Estação 3 & Estação 4 \\
\hline & rio Poxim-Mirim & rio Poxim-Açu & rioPoxim (Confluência) & rio Poxim (captação) \\
\hline Período Chuvoso & 0,12 & 0,16 & 0,05 & 0,20 \\
\hline Período Seco & 0,15 & 0,11 & 0,03 & 0,15 \\
\hline
\end{tabular}

Essa relação passa para mais de 0,10 nas demais estações amostrais, não demonstrando relações entre os períodos estudados. Observando-se a faixa de variação estudada, os valores entre 0,10 e 0,20 para a relação DBO:DQO podem ser esperados para mananciais que recebem esgotos oriundos de várias fontes (doméstica, comercial e industrial) que potencialmente contribuem tanto com compostos biodegradáveis quanto com uma parcela de compostos orgânicos de difícil degradação biológica (Bollmann e Marques, 2006). 
VASCO, A. N.; BRITTO, F. B.; PEREIRA, A. P. S.; MÉLlO JÚNIOR, A. V. M.; GARCIA, C. A. B.; NOGUEIRA, L. C. Avaliação espacial e temporal da qualidade da água na sub-bacia do rio Poxim, Sergipe, Brasil. Ambi-Agua, Taubaté, v. 6, n. 1, p. 118-130, 2011. (doi:10.4136/ambi-agua.178)
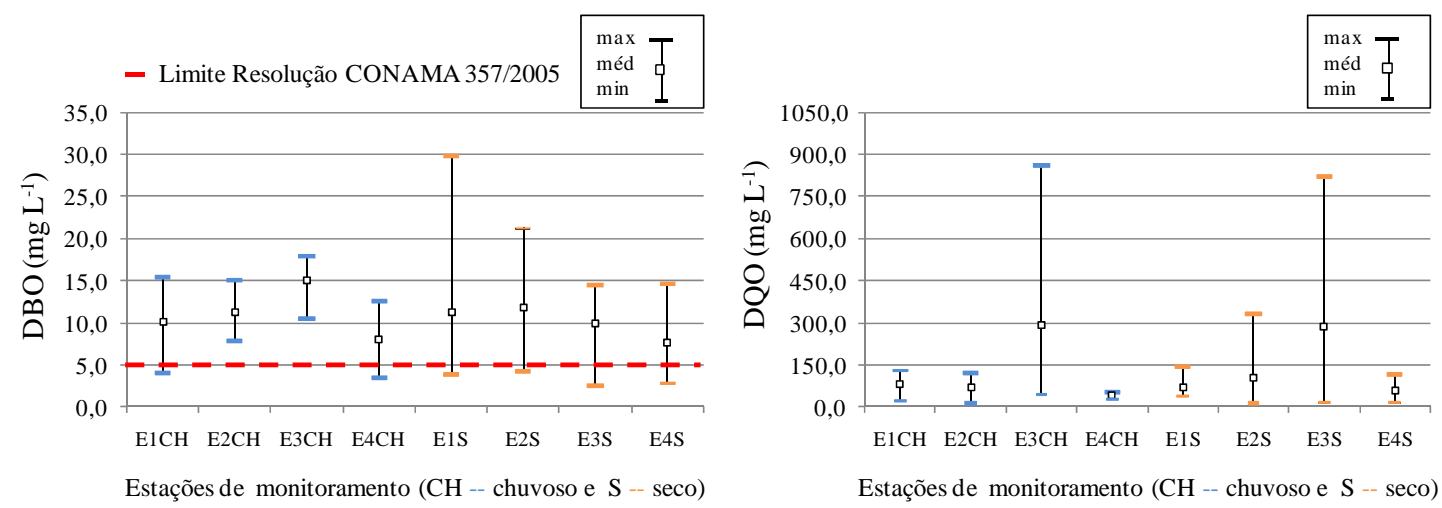

Figura 3. Valores máximos, médios e mínimos de DBO e DQO na sub-bacia do rio Poxim, Sergipe, no período chuvoso e seco, nas diferentes estações de monitoramento.

As concentrações de DQO apresentaram valores próximos em ambos os períodos. No entanto, as concentrações de DQO obtidas na estação E3 foram elevadas, com valores máximos acima de $800 \mathrm{mg} \mathrm{L}^{-1}$.

\subsubsection{Nutriente P-Total e Clorofila-a}

O escoamento da água sobre a camada superficial do solo durante os eventos pluviais é a principal fonte difusa de poluição nos mananciais hídricos. Estudos de Dils e Heathwaite (1996) e McDowell et al. (2001) mostram significativa relação entre o nível de fósforo do solo e o fósforo dissolvido no escoamento superficial. Esses estudos indicaram que, nos agroecossistemas sob sistema de cultivo convencional, os sedimentos provêm principalmente do escoamento em áreas de lavoura. Desse modo, a quantidade de fontes de poluição numa determinada sub-bacia depende da qualidade das fontes e do grau de intervenção antrópica no meio, ou seja, do sistema adotado de uso e manejo do solo (McDowell et al., 2001).

A Figura 4 mostra a distribuição do fósforo total e da clorofila-a, no período seco e chuvoso. Como pode ser observado, o fósforo total foi encontrado na água em maiores concentrações na estação E1, E2 e E3, principalmente durante o período chuvoso com valores médios de 0,076; 0,176 e 0,171 $\mathrm{mg} \mathrm{L}^{-1}$, respectivamente. Esses valores estão muito acima do limite $0,025 \mathrm{mg} \mathrm{L}^{-1}$ estabelecido pela Resolução CONAMA $\mathrm{n}^{0} 357 / 2005$, e ocorreram em agosto de 2009, quando houve um grande evento de chuva no momento da amostragem, evidenciando que as concentrações de fósforo estão relacionadas ao deflúvio superficial ocorrido na sub-bacia. No período seco, as concentrações de fósforo total estiveram fora do limite de detecção do método utilizado.
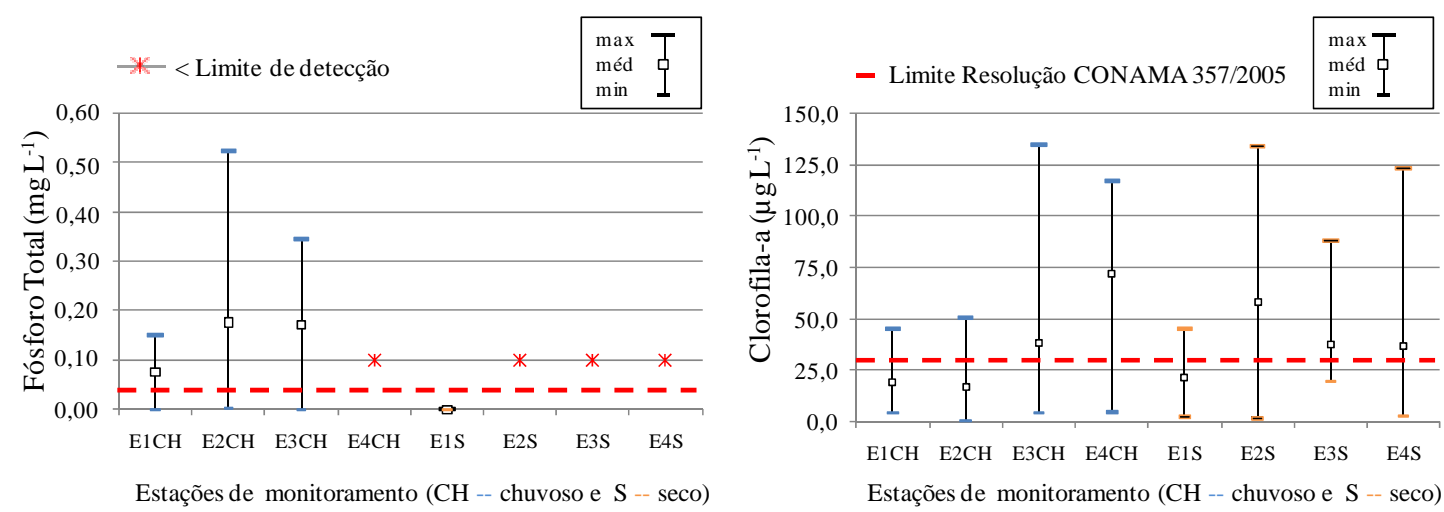

Figura 4. Valores máximos, médios e mínimos de fósforo total e clorofila-a, na sub-bacia do rio Poxim, Sergipe, no período chuvoso e seco, nas diferentes estações de monitoramento.

O crescimento de algas fitoplanctônicas no corpo d’água está relacionado com a presença de nutrientes (principalmente nitrato e fosfato), com a penetração da luz e a temperatura da 
VASCO, A. N.; BRITTO, F. B.; PEREIRA, A. P. S.; MÉLlO JÚNIOR, A. V. M.; GARCIA, C. A. B.; NOGUEIRA, L. C. Avaliação espacial e temporal da qualidade da água na sub-bacia do rio Poxim, Sergipe, Brasil. Ambi-Agua, Taubaté, v. 6, n. 1, p. 118-130, 2011. (doi:10.4136/ambi-agua.178)

água. A clorofila-a variou de 0,3 a 134,4 $\mu \mathrm{g} \mathrm{L}^{-1}$, em todo o período de monitoramento. Foram observados picos de concentração de clorofila-a no período chuvoso, nas estações E3 e E4, e no período seco, nas estações E2, E3 e E4, pois são regiões com maior disponibilidade de nutrientes, como consequência do elevado aporte antrópico.

Na região de estudo, a produção de algas é limitada pela disponibilidade de nutrientes e pela penetração da luz na coluna d’água, com pouca influência da temperatura, que não sofre grandes variações entre o período seco e chuvoso. Como o fosfato é o nutriente limitante, a produção de algas vai depender da disponibilidade de fosfato na água e do índice de insolação.

Foi observado que, em rios que apresentam uma relação inversa entre o conteúdo de fósforo e o fluxo de água, as concentrações do fósforo na água são controladas por fontes pontuais, desde que essas fontes sejam diluídas no período de alto fluxo de água (período chuvoso). Nos rios que drenam regiões agrícolas com baixa população urbana, as concentrações de fósforo aumentaram no período de alto fluxo, indicando a predominância de fontes difusas no controle das concentrações do fósforo na água (Jarvie et al., 2005).

\subsubsection{Nitrogênio na forma de Nitrato e Nitrito}

Os resultados da Figura 5 demonstram que, na estação E2, foram encontrados valores máximos de 49,2 $\mathrm{mg} \mathrm{L}^{-1}$ de nitrato, ficando a concentração, aproximadamente, 5 vezes acima do limite (10 mg L $^{-1}$ ) definido pela Resolução CONAMA n ${ }^{0}$ 357/2005. De acordo com essa Resolução, o nitrogênio é padrão de classificação das águas naturais e padrão para identificar a emissão de esgotos.

Para o nitrito, foi encontrado um valor máximo $1,23 \mathrm{mg} \mathrm{L}^{-1}$, na estação E3, onde foram identificados lançamentos no rio de esgotos sem tratamento adequado. O nitrito representa uma fase intermediária entre a amônia e o nitrato (Esteves, 1998). A presença de nitrato caracteriza uma poluição remota, em função de que o nitrogênio se encontra em seu último estádio de oxidação (Macêdo, 2003).
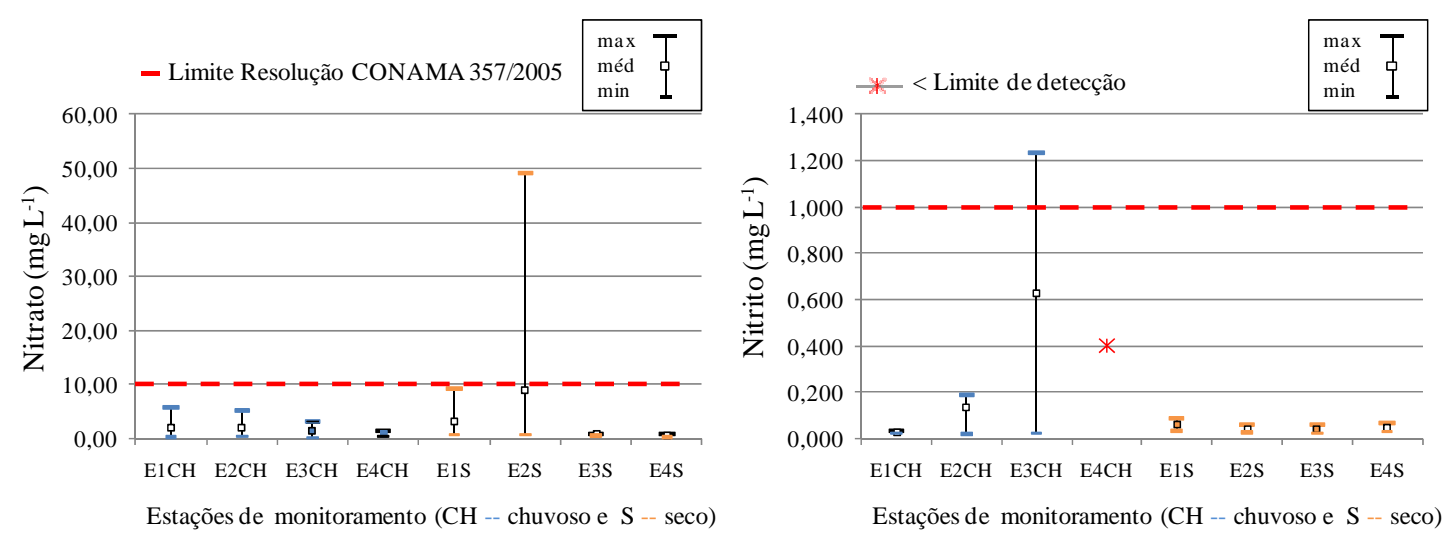

Figura 5. Valores máximos, médios e mínimos de nitrato e nitrito na sub-bacia do rio Poxim, Sergipe, no período chuvoso e seco, nas diferentes estações de monitoramento.

A poluição por nitrogênio de origem agrícola é caracterizada por uma considerável variabilidade temporal e espacial, dependendo das práticas agrícolas adotadas na região e das variáveis ambientais, como clima, solo e topografia (Giupponi e Vladimirova, 2006). A importância relativa das diversas fontes de nutriente tem, tradicionalmente, sido avaliada com base na variação do fluxo de água anual do rio (Jarvie et al., 2005). 
VASCO, A. N.; BRITTO, F. B.; PEREIRA, A. P. S.; MÉLlO JÚNIOR, A. V. M.; GARCIA, C. A. B.; NOGUEIRA, L. C. Avaliação espacial e temporal da qualidade da água na sub-bacia do rio Poxim, Sergipe, Brasil. Ambi-Agua, Taubaté, v. 6, n. 1, p. 118-130, 2011. (doi:10.4136/ambi-agua.178)

\subsubsection{Nitrogênio na forma Amoniacal}

O nitrogênio amoniacal é um indicador de poluição orgânica por despejos domésticos. Enquanto o nitrato é a forma mais comum de nitrogênio, encontrado em águas naturais não poluídas, em ambientes poluídos predominam as formas de nitrogênio orgânico e amoniacal. A presença de amônio na água caracteriza a poluição recente por esgotos domésticos, o que foi observado mais claramente nas estações E3 e E4 (Figura 6), no período chuvoso e seco, bem como na estação E2, no período seco.
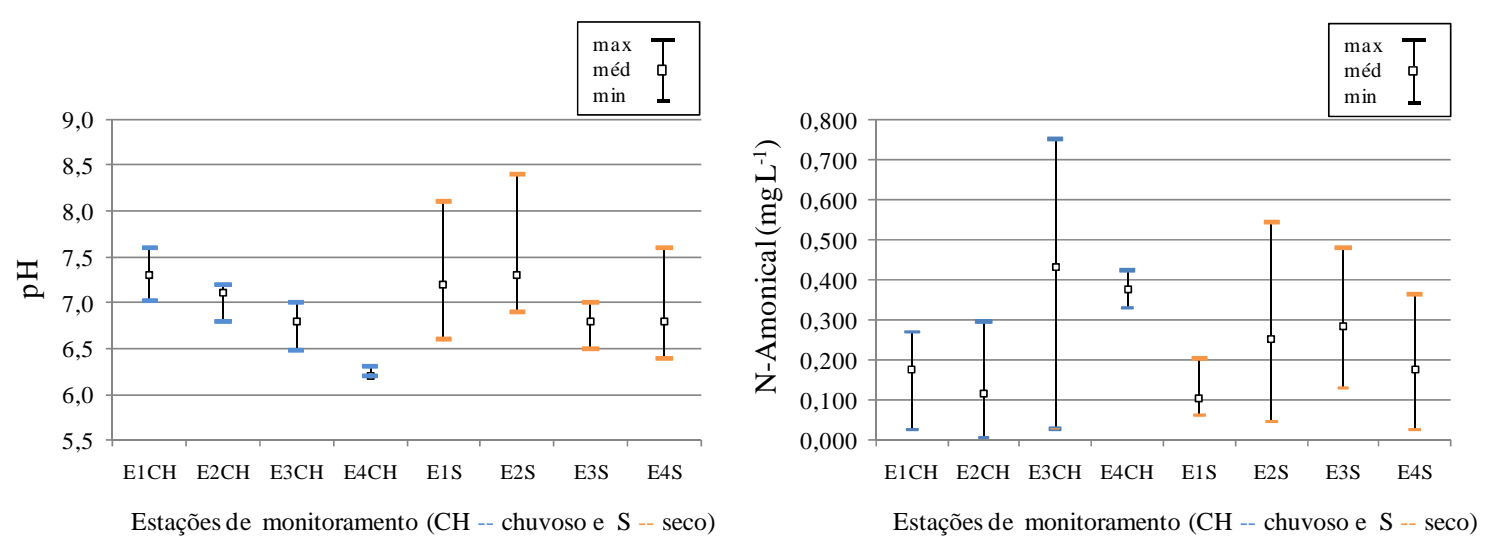

Figura 6. Valores máximos, médios e mínimos do $\mathrm{pH}$ e $\mathrm{N}$-amoniacal na sub-bacia do rio Poxim, Sergipe, no período chuvoso e seco, nas diferentes estações de monitoramento.

O nitrogênio amoniacal variou de 0,006 a $0,753 \mathrm{mg} \mathrm{L}^{-1}$, com valores médios de 0,463 e 0,376 mg L $\mathrm{m}^{-1}$, nas estações E3 e E4, no período chuvoso, e valores médios de 0,252; 0,284 e $0,179 \mathrm{mg} \mathrm{L}^{-1}$, no período seco, nas estações E2, E3 e E4. As maiores concentrações ocorreram nas estações da região com influência urbana. As concentrações de nitrogênio amoniacal ficaram dentro do limite permitido $\left(1,0 \mathrm{mg} \mathrm{L}^{-1}\right)$ pela Resolução CONAMA $\mathrm{n}^{0}$ 357/05, para águas doces de Classe 2.

\subsubsection{Sólidos em Suspensão e Turbidez}

Todos os contaminantes da água, com exceção dos gases dissolvidos, contribuem para a carga de sólidos presentes na massa líquida. Os sólidos com tamanho superior a 1 micron são classificados como sólidos em suspensão (SS), que são os responsáveis pelo aumento da turbidez das águas, prejudicando seus aspectos estéticos e a produtividade do ecossistema, pela diminuição da penetração da luz. Os sólidos em suspensão provêm do carreamento de solos pelas águas pluviais, devido a processos erosivos e desmatamentos na área da bacia (Vieira, 2008).

Os valores máximos de turbidez foram 179 e 157 NTU, nas estações de monitoramento E2 e E3, respectivamente, no período chuvoso (Figura 7). Os sólidos em suspensão provem do carreamento de solos pelas águas pluviais, devido a processos erosivos e desmatamentos na sub-bacia. Os valores de SDT não apresentaram violações durante o período de monitoramento. A Portaria $n^{0} 518 / 04$, do Ministério da Saúde, que determina o padrão de potabilidade da água destinada ao consumo humano, determina uma concentração até $500 \mathrm{mg}$ $\mathrm{L}^{-1}$ de SDT, em componentes que afetam a qualidade organoléptica. Nota-se que mesmo considerando o limite máximo, as águas dos corpos de águas apresentaram valores inferiores ao estipulado pelo Ministério da Saúde, sendo considerada potável quanto a esse requisito. 
VASCO, A. N.; BRITTO, F. B.; PEREIRA, A. P. S.; MÉLlO JÚNIOR, A. V. M.; GARCIA, C. A. B.; NOGUEIRA, L. C. Avaliação espacial e temporal da qualidade da água na sub-bacia do rio Poxim, Sergipe, Brasil. Ambi-Agua, Taubaté, v. 6, n. 1, p. 118-130, 2011. (doi:10.4136/ambi-agua.178)
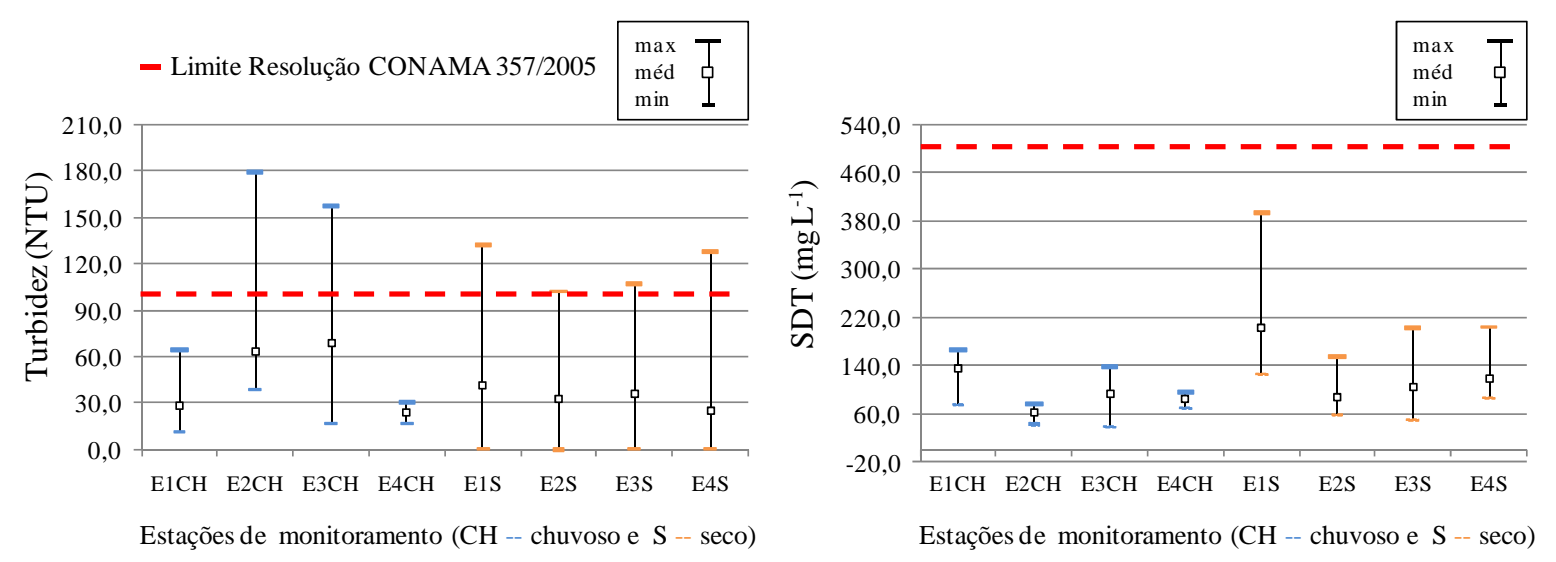

Figura 7. Valores máximos, médios e mínimos de turbidez e SDT na sub-bacia do rio Poxim, Sergipe, no período chuvoso e seco, nas diferentes estações de monitoramento.

\section{CONCLUSÕES}

As concentrações de Oxigênio Dissolvido apresentaram-se baixas nas quatro estações de monitoramento, com valores críticos nas estações E3 e E4, indicando a interferência antrópica no ambiente aquático.

Os valores da Demanda Bioquímica de Oxigênio e da Demanda Química de Oxigênio indicam maior aporte de matéria orgânica na estação de monitoramento E3, área urbana da sub-bacia sem o saneamento básico necessário.

As concentrações dos nutrientes nitrogênio e fósforo foram mais elevadas nas estações E1 e E2, localizadas na parte alta da sub-bacia que apresenta atividade agrícola. Altas concentrações de fósforo total foram determinadas apenas no período chuvoso, indicando a possível influência do escoamento superficial na contaminação por esse nutriente.

A turbidez e os sólidos devolvidos totais apresentaram valores médios abaixo do limites estabelecidos, indicando um menor comprometimento da qualidade da água por sólidos em suspensão.

\section{AGRADECIMENTOS}

Ao Laboratório de Química Analítica Ambiental da Universidade Federal de Sergipe (LQA), pela realização das análises. À Coordenação (CAPES), pela bolsa de estudo.

\section{REFERÊNCIAS}

AGUDO, E. G. Guia de coleta e preservação de amostras de água. São Paulo: Companhia de Tecnologia de Saneamento Ambiental, 1987. 150p.

ALVES, J. P. H.; GARCIA, C. A. B. Qualidade da água. In: Diagnóstico e avaliação ambiental de sub-bacia hidrográfica do rio Poxim. Aracaju: UFS/FAPESE, 2006. Relatório Interno.

AMERICAN PUBLIC HEALTH ASSOCIATION - APHA. Standard methods for examination of water and wastewater. 20. ed. Denver: APHA, 2005.

ARAÚJO, A. M. Qualidade das águas estuarinas em Recife (1995/1996). Ciência e Engenharia, Uberlândia, v. 9, n. 1, p. 32-39, 2000. 
VASCO, A. N.; BRITTO, F. B.; PEREIRA, A. P. S.; MÉLlO JÚNIOR, A. V. M.; GARCIA, C. A. B.; NOGUEIRA, L. C. Avaliação espacial e temporal da qualidade da água na sub-bacia do rio Poxim, Sergipe, Brasil. Ambi-Agua, Taubaté, v. 6, n. 1, p. 118-130, 2011. (doi:10.4136/ambi-agua.178)

BOLLMANN, H. A.; MARQUES, D. da M. Influência da densidade populacional nas relações entre matéria orgânica carbonácea, nitrogênio e fósforo em rios urbanos situados em áreas com baixa cobertura sanitária. Engenharia Sanitária e Ambiental, v. 11, p. 175-184, 2006.

BRASIL. Ministério da Saúde. Portaria no 518, de 25 de março de 2004. Normas e padrões de potabilidade da água destinada ao consumo humano. Brasília: MS, 2005. 15p. Disponível em: <http://portal.saude.gov.br/portal/arquivos/pdf/portaria_518_2004.pdf>. Acesso em: 20 dez. 2008.

BRASIL. Ministério do Meio Ambiente. Conselho Nacional do Meio Ambiente - CONAMA. Resolução $\mathbf{N}^{\circ}$ 357, de 17 de março de 2005. Dispõe sobre a classificação dos corpos de água e diretrizes ambientais para o seu enquadramento, bem como estabelece as condições e padrões de lançamento de efluentes, e dá outras providencias. Brasília: Gráfica e Editora Itamarati, 2005.

DALTRO FILHO, J.; SANTOS, D. C. G. Estudo das condições sanitárias e ambientais do rio Poxim, no trecho compreendido entre o parque dos Faróis e a captação da DESO. In: CONGRESSO DE INICIAÇÃO CIENTÍFICA, 3., 2001, Aracaju Resumos... Aracaju: UFS, 2001. v. 01. p. 20.

DILS, M. R.; HEATHWAITE, A. L. Phosphorus fractionation in hillslope hydrological pathways contributing to agricultural runoff. In: ANDERSON, M. G.; BROOKS, S. M. (Eds.). Advances in hillslope processes. New York: John Wiley and Sons, 1996. v.1. p.229-251.

ESTEVES, F. Fundamentos da liminologia. rio de Janeiro: Interciência/FINEP, 1998. 574p.

FIGUEIRÊDO, A. C. Avaliação e diagnóstico da qualidade da água do açude de apipucos, Recife-PE. 2008. 104 f. Dissertação (Mestrado em Engenharia Agrícola) Universidade Federal Rural de Pernambuco, Recife, 2008.

FRANCO, R. A. M.; HERNANDEZ, F. B. T. Qualidade da água para irrigação na microbacia do Coqueiro, Estado de São Paulo. Revista Brasileira de Engenharia Ambiental, v. 13, n. 6, p. 772-780, 2009.

GIUPPONI, C.; VLADIMIROVA, I. Ag-PIE: a GIS-based screening model for assessing agricultural pressures and impacts on water quality on a European scale. Science of the Total Environment, v. 359, p. 57-75, 2006.

http://dx.doi.org/10.1016/j.scitotenv.2005.07.013

JARVIE, H. P.; NEAL, C.; WITHERS, P. J. A. Sewage-effluent phosphorus: a greater risk to river eutrophication than agricultural phosphorus? Science of the Total Environment, v. 360, p. 246-253, 2005.

http://dx.doi.org/10.1016/j.scitotenv.2005.08.038

LUCAS, A. A. T.; AGUIAR NETTO, A. DE O.; FOLEGATTI, M. V.; FERREIRA, R. A. Calibration of hydrodynamic model MIKE 11 for the sub-basin of the Piauitinga river, Sergipe, Brazil. Revista Ambiente \& Água, v. 5, p. 195-207, 2010.

MACÊDO, J. A. B. Métodos laboratoriais de análises físico-químicas e microbiológicas. 2. ed. Belo Horizonte: CRQ/MG, 2003. 601p. 
McDOWELL, R. W.; SHARPLEY, A. N.; CONDRN, L. M. Processes controlling soil phosphorus release to runoff and implications for agricultural management. Nutrient Cycling in Agroecosystems, v. 59, p. 269-284, 2001.

http://dx.doi.org/10.1023/A:1014419206761

MELO NETO, J. de O.; LISBOA, J. P. N.; SANTANA, L. L.; SANTOS, C. Z. A.; SANTANA, C. L.; CHAGAS, R. M. et al. Aplicação de técnicas de geoprocessamento na análise da supressão da cobertura vegetal no baixo curso do rio Poxim. In: SIMPÓSIO REGIONAL DE GEOPROCESSAMENTO E SENSORIAMENTO REMOTO, 4., 2008, Aracaju. Anais... Aracaju: Embrapa Tabuleiros Costeiros, 2008.

PEDROSO, F.; BONETTO, C. A.; ZALOCAR, Y. A. Comparative study on phosphorus and nitrogen transport in the Parana, Paraguay and Bermejo rivers. In: TUNDISI, J. G. (Ed.). Limnologia e manejo de represas. São Paulo: ACIESP, 1988. v.1, t.1. p. 91-117 (Monografia em limnologia).

ROCHA, J. L. S.; REGO, N. A. C.; SANTOS, J. W. B.; OLIVEIRA, R. M.; MENEZES, M. Indicador integrado de qualidade ambiental aplicado à gestão de bacia hidrográfica do rio Juquiriçá, BA, Brasil. Revista Ambiente \& Água, v. 5, n. 1, p. 89-101, 2010.

SERGIPE. Superintendência de Recursos Hídricos. Atlas digital sobre os recursos hídricos de sergipe. Aracaju: SEPLANTEC-SRH, 2004. 1 CD-ROM.

SILVA, A. DE S.; BUSCHINELLI, C. C. de A.; RODRIGUES, I. A.; MACHADO R. E. Índice de sustentabilidade ambiental do uso da água (ISA_ÁGUA): municípios da região do entorno do rio Poxim, SE. Jaguariúna: Embrapa Meio Ambiente, 2004. 46 p.

SILVA, B. A. W.; AZEVEDO, M. M.; MATOS, J. S. Gestão ambiental de bacias hidrográficas urbanas. Revista VeraCidade, v. 3, n. 5, p. 1-7, 2006.

SILVA, L. M.; SOUZA, E. H.; ARREBOLA, T. M.; JESUS, T. A. Ocorrência de um surto de hepatite A em três bairros do município de Vitória (ES) e sua relação com a qualidade da água de consumo humano. Ciência \& Saúde Coletiva, v. 14, n. 6, p. 2163-2167, 2009. http://dx.doi.org/10.1590/S1413-81232009000600023

VIEIRA, P. A. Avaliação das condições de qualidade da água em tempo seco e durante eventos de chuvas em uma microbacia urbanizada no município de Belo Horizonte. 2008. Dissertação (Mestrado em Saneamento, Meio Ambiente e Recursos Hídricos) - Escola de Engenharia, Universidade Federal de Minas Gerais, Belo Horizonte, 2008.

VON SPERLING, M. Introdução à qualidade das águas e ao tratamento de esgotos. 3. ed. Belo Horizonte: Universidade Federal de Minas Gerais / Departamento de Engenharia Sanitária e Ambiental, 2005. 